\title{
Chief Sustainability Officers: Who Are They and What Do They Do?
}

\section{Citation}

Miller, Kathleen, and George Serafeim. "Chief Sustainability Officers: Who Are They and What Do They Do?" Harvard Business School Working Paper, No. 15-011, August 2014.

\section{Permanent link}

http://nrs.harvard.edu/urn-3:HUL.InstRepos:13350441

\section{Terms of Use}

This article was downloaded from Harvard University's DASH repository, and is made available under the terms and conditions applicable to Open Access Policy Articles, as set forth at http:// nrs.harvard.edu/urn-3:HUL.InstRepos:dash.current.terms-of-use\#OAP

\section{Share Your Story}

The Harvard community has made this article openly available.

Please share how this access benefits you. Submit a story.

\section{Accessibility}


H A R V A R D

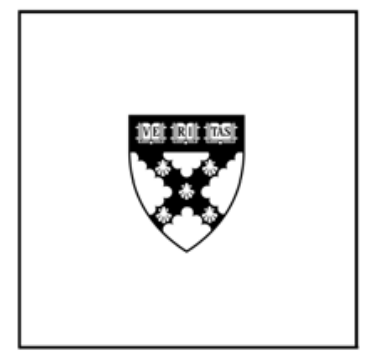

\section{Chief Sustainability Officers: Who Are They and What Do They Do?}

Kathleen Miller George Serafeim

\section{Working Paper}

15-011

August 20, 2014 


\title{
Chief Sustainability Officers: Who Are They and What Do They Do?
}

\author{
Kathleen Miller \\ Miller Consultants
}

\author{
George Serafeim* \\ Harvard Business School
}

Forthcoming as Chapter 8 in "Leading Sustainable Change," Oxford University Press

\begin{abstract}
While a number of studies document that organizations go through numerous stages as they increase their commitment to sustainability over time, we know little about the role of the Chief Sustainability Officer (CSO) in this process. Using survey and interview data we analyze how a CSO's authority and responsibilities differ across organizations that are in different stages of sustainability commitment. We document increasing organizational authority of the CSO as organizations increase their commitment to sustainability moving from the Compliance to the Efficiency and then to the Innovation stage. However, we also document a decentralization of decision rights from the CSO to different functions, largely driven by sustainability strategies becoming more idiosyncratic at the Innovation stage. The study concludes with a discussion of practices that CSOs argue to accelerate the commitment of organizations to sustainability.
\end{abstract}

Keywords: sustainability, organizational change, Chief Sustainability Officer, innovation, strategy

\footnotetext{
* Kathleen Miller is the CEO of Miller Consultants. George Serafeim is an Associate Professor of Business Administration at Harvard Business School. George Serafeim acknowledges financial support from the Division of Faculty and Research Development of Harvard Business School. We are grateful to Robert Eccles, Ranjay Gulati, and Rebecca Henderson for many helpful discussions and comments. We thank Andy Knauer for providing excellent research assistance. Contact email: gserafeim@hbs.edu.
} 


\section{INTRODUCTION}

Over the past few years, an increasing number of companies have engaged in some form of activity regarding sustainability. ${ }^{1}$ Their approaches vary widely from activities related to regulatory compliance to transforming the corporate identity. A review of the literature suggests that firms frequently go through stages starting with simple, easy to implement actions and progressing towards more complex and potentially rewarding approaches (Mirvins and Googins 2009; Hoffman and Bansal 2012). While the studies and resulting models differ in the number and nature of the stages, most suggest that nearly all companies first engage with sustainability by focusing on compliance. Their actions are neither coordinated nor strategic. Many companies eventually evolve to a more strategic sustainability approach that centers on increasing efficiencies and impacting the companies' bottom lines. For example, they may look for ways to cut their energy or water usage. At this point strategies tend to be characterized by transitional change aimed at improving existing organization practices or moving from an existing practice to a new one. Some companies move beyond transitional adjustments to transformational change in which they focus on innovation and reframe their corporate identities. It is at this point that sustainability tends to be integrated into the core business strategies and is no longer positioned as "bolt on" activities only marginally, if at all, related to the companies' business models (Eccles and Serafeim 2013).

The literature indicates that CEO commitment is critical to successful implementation of sustainability strategies (Eccles, Miller and Serafeim 2012). However, there is little research exploring how companies plot a course and transition from one stage to another. One recent trend has been the increasing appointment of Chief Sustainability Officers (CSOs) to drive the formulation and execution of an organization's sustainability strategy. The number of CSOs has grown substantially over the past few years, and while the growth has leveled off, companies are continuing to create and fill these positions. The number of companies with a full-time sustainability officer doubled between 1995 and 2003, and doubled again between 2003 and 2008 (Greenbiz 2013). We draw on a review of the literature on CSOs as well as our own study of CSOs to examine how the authority and responsibilities of CSOs differ across sustainability stages.

We begin by conducting a short review of the literature on the stages of change towards sustainability. We refer to theories from institutional and other organizational change research to address the question of what catalyzes organizations to move beyond compliance into more complex and strategic stages. After that we narrow our focus to the role of the CSO in leading change. We discuss what previous research has shown concerning the roles and characteristics of CSOs followed by a description of our own research of CSOs and other managers with primary responsibility for sustainability. In addition, we examine the mechanisms that CSOs employ to lead change. Finally, we include suggestions from CSOs on practices that have been successful in embedding sustainability in organizations with specific examples for illustration. We conclude by summarizing the relationship of our findings to the broader field of research on sustainability and organizational change.

While our data do not allow us to make any definitive claims about how the CSO, as a change agent, affects the financial performance of an organization, we use our survey and

\footnotetext{
${ }^{1}$ Sustainability is the ability to endure. From a societal perspective, sustainability means meeting the current needs of our society in ways that enable future generations to meet their own needs. Therefore, corporate sustainability is defined as a system of corporate strategy, business model, and operations that integrate economic, environmental, social, and governance factors to create and deliver products and services.
} 
interview data to advance hypotheses about the role of the CSO in leading change. Our first main finding suggests that a CSO is decentralizing decision rights and allocates responsibilities as the organization increases its commitment to sustainability $\left(1^{\text {st }}\right.$ stage being Compliance, $2^{\text {nd }}$ Efficiency, and $3^{\text {rd }}$ Innovation). In other words, one could say that the CSO, although she gains more authority, she becomes less central in later stages of sustainability. Our second main finding relates to why this is the case. We advance a hypothesis and present field data that are consistent with the hypothesis that a firm's sustainability strategy becomes significantly more idiosyncratic in the later stages of sustainability. While most companies have fairly generic sustainability strategies in the initial stages (Compliance and Efficiency), in the latter Innovation stage the sustainability strategy is more customized to the needs of different organizations and driven by the demands of the markets where an organization has a presence or plans to expand in the future.

Our analyses suggest that in terms of formal authority, the likelihood that the manager with primary responsibility for sustainability has the title of a CSO versus a lower level title increases monotonically as companies move through the stages of commitment to sustainability. Likewise the probability that she reports to the CEO or the Board of Directors increases for companies that are in later stages of sustainability commitment, suggesting higher CSO authority. In the Innovation stage, the frequency with which ultimate responsibility for sustainability rests with the CEO or the Board decreases significantly, further reflecting that the role of the CSO has matured at the stage. The probability of the Board having a separate sustainability committee is significantly higher in the Innovation stage. We interpret this finding as further evidence of increased authority as now the CSO has the assistance and also supervision of the board.

In terms of responsibilities we find that almost all CSOs in the first two stages (Compliance and Efficiency) perform a generic set of activities such as formulating and executing a sustainability strategy, identifying material sustainability issues, learning from external sources, reporting sustainability data, managing stakeholder relations and educating employees about sustainability. In contrast, in the Innovation stage we find a significantly lower frequency of CSOs engaging in most of those activities. We turn to our interview data to understand why and we find that this could be attributed to organizational needs becoming more idiosyncratic and CSOs decentralizing activities and decision rights.

Finally, the factors that affect the decision of where in the organization to locate the person who holds the primary responsibility for sustainability, differs across the stages. We find that the importance of the location of sustainability champions and the type of sustainability strategy of each organization increases monotonically across stages. This last finding is consistent with the observation that organizational needs become idiosyncratic in later stages. As a result sustainability strategies also become more idiosyncratic thereby influencing more where to locate authority on sustainability issues.

With this study we make a contribution to the literature on corporate sustainability by describing the evolving responsibilities and authority of a potentially key change agent in the firm, the CSO. While a number of studies have identified country, industry and firm characteristics that are associated with corporate commitment to sustainability (McWilliams and Siegel 2001; Campbell 2007; Ioannou and Serafeim 2012), none of the studies has examined how CSO characteristics relate to the stage of sustainability of different organizations. With this study we attempt to provide preliminary evidence to shed light on what CSOs are doing in the 
different stages of sustainability. We view this as a first step towards understanding better how CSOs enable the change process inside organizations.

\section{STAGES OF SUSTAINABILITY: LITERATURE REVIEW}

While the terminology and details vary, much of the literature on corporate sustainability refers to a series of sequenced stages that companies traverse (e.g. Nidumolu, Prahalad and Rangaswami 2009; Willard 2012; Arbogast, Thornton and Bradley 2010; Dyllick and Muff 2013). As companies move through the stages, they increase their interactions with stakeholders, assume more complex responsibilities, and attempt to align their business model with sustainability goals. Moreover, the stages represent the degree to which sustainability is strategic and central to the organization. First companies initiate activities that are related to compliance with an evolving set of regulations. During this stage, company efforts are rarely connected to business strategy or coordinated centrally. Subsequently companies begin to become more strategic by seeking ways to achieve organizational efficiencies that will impact their bottom line. To accomplish these goals, they begin to build the business case to legitimize their efforts. While some companies never move beyond their focus on efficiencies, others shift to a more advanced transformative and innovative stage by integrating sustainability into the core of the business. As company efforts become more strategic, leaders create systems, business models, operations, and procedures that seek to maximize long-term profitability while tackling societal problems and minimizing negative externalities. Company leaders claim that their impact on society increases in this stage as do the benefits and returns to the company, although rigorous empirical evidence is still lacking to prove this point.

Eccles, Miller and Serafeim (2012) suggest that endogenous or exogenous forces or a combination of both can lead to sustainability-related change. Using survey data they showed that the initial stimulus tends to come from two elements that are closely related: a strong conviction from the leadership of the organization, usually the CEO, (endogenous change) and/or external engagement, sometimes in the form of external activism or pressure from shareholders (exogenous change). When leadership commitment drives the process, it usually comes from the personal resolution of a CEO. When external engagement drives the process, it is often in the form of societal activism or pressure from stakeholders. For example, public upheaval about enzymes transformed the corporate culture of Novo Nordisk and made the company an example of one that balances all stakeholder interests. Likewise, accusations about violations of human rights led Nike to transform itself into a business that takes stakeholder accountability very seriously. As a result, Nike strives to operate responsibly in its supply chain. These findings are consistent with the literature on institutional and organizational change which indicates that the impetus for change can come from exogenous events or endogenous pressures (Meyer, 1982).

Once the CEO initiates a sustainability-related change, whether due to endogenous or exogenous forces, she seeks assistance from others. Some scholars argue that a leader alone cannot create change. Rather, they posit that organizational change occurs through social exchanges. Thornton, Ocasio and Lounsbury (2012) state that 'social interactions provide the key motor that reproduces, alters, or transforms practices and organizational identities.' While a CEO may initiate change by creating a new vision, it is the social interactions that create the common understanding and shared vision that predicate action (Demers 2007). Often the rationale of a CSO appointment is that while the CEO can retain sponsorship of the change, a CSO in a centralized position can oversee the development and implementation of the strategies that will 
carry the company through the more complex stages of change. As early as 2007, the New York Times recognized this trend: "These are not simple environmental watchdogs there to keep operations and regulators at bay. The new environmental chiefs are helping companies profit from the push to go green.",2

To understand how companies move from one stage to another, we need to better understand who the CSO is and what she does. As a leader of change towards sustainability, her responsibilities and organizational authority and relations with the ultimate centers of decision making in a company (CEO and Board of Directors) are important factors to consider in assessing her ability to be effective. Organizational research suggests that not all actors are equally successful in implementing change. The change agent's expertise, experiences, location in the structure of an organization and organizational responsibilities are important factors in her success (Kellogg 2011). For example, Lounsbury (2001) found that universities which made a greater commitment to waste recycling were the ones that employed staff with the relevant expertise and who had the commitment to develop and advocate for the introduction of new, more sustainable practices. The question then is whether the CSO can be a successful change agent. Perhaps her appointment is merely a symbolic action representing potential isomorphism. Under this scenario, the CSO has little power to affect the organization. Our survey data, explained in the following section, show that organizations differ in where they place the CSO in the corporate hierarchy, a frequently used measure of power within an organization. In some organizations CSOs report directly to the CEO or the board of directors. In other organizations they are two or three steps removed from the CEO. This suggests differences in the power that CSOs wield across organizations.

\section{CSO LITERATURE REVIEW}

Senior corporate executive positions are often created in response to significant opportunities and risks emerging from technological or social disruptions. Examples represent the creation of Chief Technology Officers (CTOs), Chief Information Officers (CIOs), Chief Quality Officers (CQOs), Chief Financial Officers (CFO) and more recently CSOs. Another example that emerged in the late $19^{\text {th }}$ century is the Chief Electricity Officer in response to the invention and commercialization of electricity.

Similar to other relatively new C-suite positions, such as Chief Technology Officers (CTOs), and Chief Information Officers (CIOs), the CSO role is evolving. ${ }^{3}$ For example, the CIO position used to be viewed as primarily a support function. Computing was initially seen as a back office tool for automating accounting and other financial matters. Later, when computers became more sophisticated and took on additional tasks throughout businesses, the title changed to director of management information systems. The breakthrough came in the mid-1980s, when chief executives increasingly invited their IT professionals to sit at the table with other C-suite executives. ${ }^{4}$ The role of the $\mathrm{CIO}$ is now more integrated into the innovation and transformation

\footnotetext{
${ }^{2}$ See Deutsch, Claudia H. “Companies Giving Green an Office.” New York Times, July 3 ${ }^{\text {rd }}, 2007$.

http://www.nytimes.com/2007/07/03/business/03sustain.html?pagewanted=all.

${ }^{3}$ National Association of Corporate Directors. "C-Suite Expectations." 2013.

http://www.nacdonline.org/files/FileDownloads/PDF/C-Suite\%20Expectations_1364247261983_2.pdf

${ }^{4}$ See IBM. "The Emergence of the CIO." 2011. http://www-

03.ibm.com/ibm/history/ibm100/us/en/icons/emergenceofcio/.
} 
parts of the business. ${ }^{5}$ With technology embedded in every facet of business, and data becoming a necessary asset in order to obtain a competitive advantage, the CIO's role is more necessary to a business today than ever before.

Similarly, the role of the CFO has been evolving. While CFOs used to be viewed as bean counters, over time their scope has broadened to include an involvement in compliance, technology, and external reporting. The history of CFOs indicates that as the number of company stakeholders increased, the scope and significance of the CFO's job also increased. Now the function involves preserving the reputation of the business, risk-management, and support for decision-making. Changes to the structure and demands placed on finance teams are transforming career paths and core capabilities needed by finance professionals. ${ }^{6}$ Their more prominent role in management is leading to a move away from basic processing and control, towards greater involvement in development and execution of business strategies.

Research on CSOs is currently limited. While there are a few practitioner survey studies examining their backgrounds and their roles, the samples in these studies tend to vary greatly. Nevertheless, a few patterns emerge that are worth our consideration as they are relevant to our understanding of a CSO's role and how they lead change. We note that below we refer to CSOs as all people with primary responsibility for sustainability in an organization even if their title is not CSO but a vice president or a director.

In terms of professional background, surveys suggest that more than half of those filling the CSO position moved from other positions inside of their companies (Greenbiz, 55\%; Weinreb Group, 86\%). Most had been employed for an average of 15 to 20 years (Acre, 2012) and moved from departments such as External Affairs, Operations, Research, Marketing (Weinreb Group 2011) or Environment, Health and Safety (EHS) (Greenbiz 2013). Footprint Talent and WAP (2011) surveyed a group of 254 business professionals including CEOs, COOs, VPs and HR execs about their perceptions of the necessary education for being a CSO. Fifty percent indicated that a business and financial background was required. Thirty-six percent reported the need for an MBA, 30\% said a communications background, and 31\% said engineering. The same study reports that when asked about desired previous experience, $53 \%$ said operations background, $43 \%$ said a science background, and $44 \%$ said product development.

In terms of authority inside the organization, the evidence is conflicting. Some surveys suggest that approximately 30\% report to the CEO (Weinreb 2011; Acre 2012). Other surveys indicate that less than 10\% of CSOs report to the CEO (Greenbiz 2013; PwC 2012). In these studies, the largest percentage of CSOs (13\%-30\%) reports to External Affairs.

Almost all of the studies cited above indicate that strategy development is a key responsibility of the CSOs. However the additional responsibilities reported in these studies were not consistent. Some of these additional responsibilities included reporting, internal engagement, and external engagement. Twenty three percent of the respondents included developing the business case as a key CSO responsibility currently and 30\% reported that this would be a key responsibility over the next five years (PwC 2012).

In sum, the literature reveals inconsistencies in the role of CSOs. Titles and responsibilities of those who are primarily responsible for sustainability vary considerably across companies. However a few patterns did emerge. Most CSOs are assigned to this role while being

\footnotetext{
${ }^{5}$ Ernst \& Young. "The DNA of the CIO." 2012. http://www.ey.com/GL/en/Services/Advisory/The-DNA-of-the$\mathrm{CIO}$

${ }^{6}$ PwC. "Evolution of the CFO." 2013. http://pwc.com.au/consulting/assets/publications/Evolution-CFO-Jul13.pdf.
} 
with the company already and have limited backgrounds in sustainability before their appointments to this position. Almost all of the CSOs have responsibility for sustainability strategy, however their additional responsibilities vary.

Importantly, while existing CSO studies yield some insights, they do not shed light on how the CSO position differs across the different stages of sustainability. Specifically, none of the previous studies analyzed how titles, responsibilities and organizational characteristics related to the different stages of sustainability. Analyzing these factors allows us to better understand how the role of the CSO evolves as organization move from one stage to another.

\section{METHODS}

\subsection{Rationale}

We used two interrelated methodologies to gather data on CSOs. First we conducted an on-line survey to establish the general framework of who they are, where they come from and what they do at varying stages of companies' sustainability commitments. Subsequently, we used the framework that we were able to establish through the results of our survey to craft interview questions that would allow us to paint a more detailed and clearer picture of how they actually function in companies known for their leadership in sustainability.

We emphasize that we do not suggest that the elements described here causally relate to the stage of sustainability. On the one hand, the role of the CSO is likely to evolve and adapt to serve the organization's needs. On the other hand, the evolving role of the CSO might lead the firm to move from one stage to the next. Or both the CSO and the firm adapt to each stage and guide movement from one stage to the next. Our results suggest correlation rather than causality. Nevertheless, they provide insights into what a CSO does and how she does it inside organizations that are in different stages of the sustainability journey.

\subsection{Methodology}

Survey Methods. We announced the survey on the Bloomberg Sustainability website and invited CSOs (or their equivalents defined as those who have primary responsibility for sustainability within their organizations) to participate. While we broadly use the word CSO throughout the paper, many respondents in our survey with primary responsibility for sustainability have different titles. In addition, we announced the survey to LinkedIn CSO-related groups and sent out invitations to individuals in all of our sustainability-related networks. The survey was conducted over a 6-week period from the end of October to early December, 2013. The survey consisted of 17 questions pertaining to roles and responsibilities for sustainability, involvement of the Board and the CEO, how and by whom the CSOs were chosen for their positions, and the nature of their reporting relationships. One-hundred-thirty CSOs or their equivalents with different titles completed the survey. Sixty-six of those who responded had primary responsibility for sustainability in the organization and completed the whole survey providing us with the data we needed. We analyzed only these responses for two reasons. First, we were not sure whether more junior employees would have the necessary information to answer the questions, as many are strategic in nature. Second, requiring that all respondents have primary responsibility ensured a higher level of cross-firm comparability in respondents. 
The participants in the survey (66 respondents) represented 27 industries with Professional Services comprising 20\%, Financial Services 14\%, Consumer Goods 13\%, Energy $12 \%$, Construction 12\%, Technology and Communications 8\%, Agriculture, Mining and Water $6 \%$ and other industries the remaining $15 \%$. The majority of participants came from companies that had at least 10,000 employees so our sample mainly represents very large companies. Companies with under 500 employees comprised 23\% of the sample, those with 500-1000 6\%, those between 1000 and $10,00026 \%$ and those with over 10,000 employees $46 \%$. The respondents represented organizations that had operations in Australia-New Zealand 32\%, North America 25\%, Global 24\%, Europe 21\%, Asia Pacific 18\%, Latin America 10\% and AfricaMiddle East $10 \%$.

In the survey we asked participants to identify the organization's primary approach to sustainability. We provided three choices: Compliance with regulations and securing license to operate, Efficiency and focus on the bottom line, and Innovation and exploitation of opportunities for Growth. The three stages are broadly consistent with the stages of sustainability we reviewed in section 2. We kept responses anonymous so as to avoid respondents overestimating the sustainability stage of their organization. The equal split between respondents across the three stages, 22 each, suggests that there is no obvious tendency of respondents to overestimate their organization's stage; something that would be apparent if we had received a very low number of respondents identifying their organization at the Compliance stage. That being said we have no way to completely rule out the possibility that some respondents misclassified their organizations adding noise to our results.

Interview Methods. We conducted a series of interviews to complement our survey data. Our intention was to gain a better understanding of how the CSO impacts the transition of an organization from one stage to the next. In addition, we wanted to explore whether the CSOs see themselves as leaders of change, and if so, how they approach this responsibility. In choosing who to interview, we focused on companies that appeared to be either at the Efficiency or Innovation stage. Our reasoning was that we wanted to gather more detail about the nature of their experiences in each stage and learn about the steps that their companies had taken as they moved through the initial stages. We based our criteria for selection on whether the company was integrating sustainability-related elements into their products or services based on disclosures made by the company. Most of our interviewees came from large, global companies, although a few were from not-for-profit organizations both large and small. We asked them to describe how their companies had first gotten involved in sustainability including what motivated them and what approach they took in the beginning. Then we asked them to describe what had happened between that initial involvement and the current company status. We inquired about when and how a business case had been developed and what their role in the development had been. We questioned them about when their position had been created and why. We obtained detail on their roles in the past and in the present, and what their role would be in the projected future. Finally we asked them whether they considered themselves to be change leaders, and if so, what approach they were taking. Interviews were done by phone between January $7^{\text {th }}$ and $21^{\text {st }}$. Each interview lasted approximately 45 minutes. In total we interviewed twelve CSOs.

Most of the interviewees had served as the CSO for four years or less. They indicated that this is a typical CSO tenure currently. Consistent with what we found in our literature review, most had been in other positions within their companies before appointed to be the CSO. While those in this group of internal appointees had not been in formal positions related to 
sustainability, several had been involved with sustainability-related activities as either volunteers or in some other peripheral capacity within their companies. Their prior work included positions in areas such as marketing, human resources, plant engineering, compliance, procurement, IT, printing and production management. Most were not formally educated in sustainability-related fields. Rather their educational credentials included fields such as architecture, biology, and engineering, among others. The Board or the CEO had appointed all of them, and most of them reported to one or the other.

The profiles of those few who were hired from outside of the company differed from those who were appointed from within. They had educational credentials and previous experience in sustainability-related fields. Even though their backgrounds differed from internally appointed CSOs, the Board or the CEO of the hiring company chose them as well. Steve Howard, the CSO of Ikea, a Swedish company that sells home furnishings, appliances and accessories, told us that the role of the CSO is evolving as companies' sustainability strategies are evolving. Similar to the Chief Information Officer (CIO) or Chief Risk Officer (CRO), over time, the role is becoming more "professionalized". 7 Howard suggested that as companies begin to take on more complex issues and integrate sustainability into the core of the business a CSO with the related education and experience is a better fit for the position. He suggested that the trend is now moving in the direction of hiring CSOs who are able to take an informed approach to sustainability strategies as a result of their prior education and experience.

Upon hearing details from those we interviewed, we determined that the companies they represented ranged from the high end of the mid-level stages i.e. efficiencies and building their business case, up through the highest stages involving innovation and transformation for solving world problems. This is by construction since we screened companies to interview based on their integration of sustainability factors in their products and services. All of the CSOs were responsible for at least assisting with if not wholly owning the development of the sustainability strategy. All were accountable for overseeing the integration of sustainability into the organization, with some playing a more hands-on role than others. All see themselves as change leaders. Most are in influential positions in which they report to the CEO and or the Board of Directors, and most sit on the Executive Committee.

\section{RESULTS}

\subsection{Compliance Stage}

The Compliance stage represents the point when most companies first engage with sustainability. Thirty-three percent of our survey sample indicated that their companies were in this stage. Very few of the respondents have the title of CSO in this Compliance stage (14\%), far fewer than in the next two stages (Efficiency 27\%; Innovation 36\%). All results are reported in Figure 8.1. The largest percentage have the title of Director of Sustainability (27\%), indicating either that a lower level title such as Director is more likely in this stage or, alternatively, more of those who fall into this category with the title of Director versus Chief chose to participate in the survey. Nevertheless, no matter what their title, when CSOs are appointed in this early stage, as opposed

\footnotetext{
${ }^{7}$ See the following article discussing the professionalization of the CIO: Spitze, James M. "How to unlock the power of the CIO." Wall Street Journal, August 1, 2012. http://blogs.wsj.com/cio/2012/08/01/how-to-unlock-thepower-of-the-cio/
} 
to the later stages, they have a greater positive influence on the involvement of the CEO. The likelihood that the appointment of a CSO will increase CEO involvement in sustainability declines monotonically as they move from the Compliance stage to Efficiency and then to Innovation. Most likely the CEO of a company in the later stages is already very involved in the sustainability strategies and as a result the appointment of a CSO is unlikely to increase their commitment.

Figure 8.1 also reports that although in most cases $(77 \%)$ the CEO or the Board made the decision of where to position the CSO or equivalent, only 32\% report to the Board or the CEO. In this stage almost all CSOs are responsible for developing strategy, reporting sustainabilityrelated data, embedding sustainability into the organization, determining the material sustainability issues, and learning about sustainability from other companies. Based on these findings, we conclude that during the Compliance stage, those primarily responsible for sustainability have a wide range of responsibilities but are not positioned for high levels of authority.

Our interview data corroborated that their companies began their involvement in sustainability through regulatory compliance. They confirmed that the activities were neither strategic nor centralized. Some reported that in addition to compliance, voluntary employee initiatives such as recycling projects or green teams also appeared during this stage. However these activities were not seen as strategic and were rarely coordinated centrally.

Most of the CSO's we interviewed had some role in the company's sustainability activities during the Compliance stage even though they did not hold the title of CSO. In some instances the activities were voluntary and outside of their formal job responsibilities, while in other cases these tasks were part of a formal role that encompassed other related activities. For example, John Edelman, the CSO for Edelman, the largest PR firm in the world, reported that during their initial stage of engagement with sustainability much of the activity was through employee volunteer efforts. However, he said that the initiatives were not coordinated, and no one in the organization had knowledge regarding all of the activities. Edelman, as with most of those we interviewed, became an advocate for centralizing and coordinating the oversight of the sustainability initiatives. He also assisted in the creation of the CSO job and was subsequently appointed to it in order to spearhead the company's movement from compliance to efficiency. One of his highest priorities during his first year as CSO was to take an inventory of the sustainability-related activities and to create a global framework for central oversight with local execution as they moved into the Efficiency stage of sustainability.

On the other hand, Dave Keppler, the CSO for Dow, was the senior executive for EHS and Corporate Social Responsibility before he became the CSO. He too became an advocate for the position and helped design it before being appointed to it. These advocates helped move the company to a higher level of commitment. Thus they were leaders in assisting the company in transitioning from Compliance to the Efficiency stage. Then, as the companies began to move towards Innovation, they helped develop the CSO position and were appointed to it. Interestingly, our interviewees often already had a relationship with the CEO and/or the senior leaders even before they became CSO. Even though some were in higher levels of authority than were others, it is possible that their existing relationship with the CEO allowed them greater credibility as advocates.

In summary, our data validate the hypothesis that most companies at the Compliance stage do not have a formal CSO position. Our survey data suggest that if they have anyone at all who is dedicated to sustainability, the role tends to be a lower-level position not reporting 
directly to the CEO or the board of directors. We recognize that our interview data is not robust enough for definitive conclusions. However, our limited data do reveal a consistent pattern that can be tested in future studies. In most cases a leader within the organization, often without the title of CSO, becomes the advocate for the company's increased commitment to sustainability. In general this person has already engaged in some sustainability-related projects in the company either outside of her formal position or as a small part of it. They also appear to have had a relatively strong connection with the CEO during this early stage. Thus the advocate is credible and well-positioned to drive the change successfully. Our survey data seems to corroborate this conclusion in that when a company does have a CSO (or someone with equivalent responsibilities), she is likely to have a positive influence on the CEO's involvement in sustainability as the company moves from the Compliance stage to the Efficiency stage

\subsection{Efficiency Stage}

In this stage, companies begin to move to a more strategic approach to sustainability. They begin to focus on how they can respond to stakeholder pressures and at the same time impact the company's bottom line through actions such as reducing waste and increasing resource efficiency. They also begin the process of sustainability legitimization by building the business case and engaging internal stakeholders in the interactions that lead to common understanding. Hans Wegner, the CSO of National Geographic, one of the world's largest non-profit scientific and educational institutions, explained in our interview how the organization entered the second stage of sustainability. National Geographic was reporting on climate and social crises around the world and yet as an organization they were not doing much themselves to address the issues. These endogenous tensions led Wegner to push the organization for a greater commitment to sustainability. At the time, his job was to oversee production of the magazine including its printing, publishing and distribution. He organized a group of volunteers around the company to design and assist with a variety of sustainability-related projects. He led the volunteers in the development of a sustainability vision and acquired the sign-off of the CEO. It was at this point that National Geographic pursued a new goal of becoming a triple bottom line company. Subsequently, they have set targets to become carbon neutral and are moving towards zero waste with projects such as magazine life-cycle analysis. They are also focusing on policies and practices that would enable them to improve their resource efficiency and address employee health. These goals and actions place them squarely in the Efficiency stage, which they entered due to endogenous pressures. Wegner, the current CSO, was instrumental in moving the company from Compliance to Efficiency through his advocacy and organizing work.

Figure 8.1 shows that $33 \%$ of our sample falls in this stage. Those who have the title of CSO rose to $27 \%$ in this stage and is almost equal to the percentage that has the title of Director of Sustainability (31\%). The Board and/or CEO places a lower percentage of CSOs on the organizational chart in this stage compared with both of the other two stages (64 vs. 71\%). They are more likely to base the positioning of the CSO on the breadth of the company's involvement with sustainability compared with the other two stages. And they are more likely to position the CSO to report to the CEO or the Board in this stage vs. the Compliance stage (41\% vs. $32 \%)$. While the appointment of the CSO is less likely to increase the involvement of the CEO in this stage, the ultimate responsibility for sustainability is more likely to be attributed to the CEO than in either of the other two stages (86\% versus $73 \%$ in the Compliance stage and $59 \%$ in the Innovation stage). 
Similar to the Compliance stage, almost all CSOs are responsible for developing strategy, reporting sustainability-related data, embedding sustainability into the organization, determining the material sustainability issues, and learning about sustainability from other companies. In addition, they are likely to be involved in educating employees about sustainability. Even though the categorical responsibilities resemble those of the persons responsible for sustainability in the Compliance stage, the nature of the tasks attached to these responsibilities are likely to shift in this second stage. In the Compliance stage, the responsibilities primarily tend to center on how to comply with environmental regulations, while in the Efficiency stage the same responsibilities are more likely to be on how to address a variety of stakeholder concerns, how to protect or enhance the company reputation, and how to impact the company's bottom line through reducing waste and increasing efficiencies in the use of resources.

We interpret the findings around the increased authority of the person primarily responsible for sustainability as evidence that companies are evolving to become more strategic throughout the second stage. The CEO along with the senior leadership team is already involved in sustainability and the CEO has already taken the lead when the CSO is appointed. Thus, the CEO continues to work in partnership with the new CSO. In cases where the person who is appointed to the position of CSO is already playing a leadership role in the company as were most of our interviewees, this partnership is a natural extension from the earlier stage. Since the company is most likely in the initial phases of developing the business case and crafting its strategy, it makes sense that the positioning of the CSO would be based on the breadth of the company's commitment to sustainability at this point. Undoubtedly the breadth of their commitment varies at this stage from company to company as company leaders sort out what should be included in the strategy. In contrast, the importance of where champions of sustainability exist in the organization and the nature of the sustainability strategy of the organization increases in importance for positioning the CSO as the stages progress from Compliance to Efficiency to Innovation.

Consistent with these survey results, our interview data indicate that it is in this stage that the companies are most likely to hire or appoint a CSO. For example, Peter Graf, the CSO of SAP, the world's largest inter-enterprise software company, told us that in 2008 he proposed to the CEO and the Board that SAP make a stronger and more strategic commitment to sustainability. He made the case based on the ROI of increasing efficiencies. At the time he was the Executive Director of Marketing. He said that the leadership accepted his proposal quickly. He was appointed to the newly created position of the CSO within a few months and assisted the company in moving from Compliance to Efficiency. Upon his appointment, he was instrumental in developing the business case and communicating it to the appropriate stakeholders in order to legitimize sustainability endeavors. With his background in Marketing, he was in a good position to advocate for moving the company into the Innovation stage. Graf said that as the company moved into a market-driven and Innovation stage, he was once again responsible for crafting the business case and tailoring how it was communicated to various stakeholders. The move from Efficiency to Innovation was a natural and quick process for SAP, according to Graf. SAP found that the technologies they developed to reduce their own footprint in the Efficiency stage were also attractive to their customers. Therefore, they took the opportunity to commercialize and readily moved into the Innovation stage.

\subsection{Innovation Stage}


As companies move into the Innovation stage, they begin to take a proactive and transformational approach to sustainability rather than the more reactive approaches that characterize the first two stages. The strategies become market-driven, with a focus on innovation and often addressing societal problems, such as climate change, water management, and obesity.

Figure 8.1 shows that $33 \%$ of our sample falls into the Innovation stage. Just as the number of people with the title of CSO increases from the Compliance to the Efficiency stage, it increases again from the Efficiency to Innovation stage (27\% to $36 \%$ ). The frequency of the CEO being named as holding the ultimate responsibility for sustainability drops in this stage to $59 \%$ (compared to $73 \%$ in Compliance and $86 \%$ in Efficiency stage). We believe that this finding implies that the CSO role has evolved and matured in this stage, and that the ultimate responsibility shifts from the $\mathrm{CEO}$ to the CSO accordingly. Certain factors which affect where to locate primary responsibility for sustainability within an organization are more prominent in the later stages. In the Innovation stage, $36 \%$ thought the location of sustainability champions had an affect (compared to $18 \%$ in the Compliance stage and $23 \%$ in the Efficiency stage) and $64 \%$ thought the organization's sustainability strategy had an affect (compared to $41 \%$ in the Compliance stage and 55\% in the Efficiency stage). The incidence of the Board having a special committee on sustainability increases dramatically in the Innovation stage $(64 \%$ vs. $32 \%$ in Compliance and $27 \%$ in Efficiency stage). These findings imply that sustainability has achieved a new level of strategic focus and that its importance has become significant enough to warrant increased discussion by the Board.

Interestingly, the responsibilities of the CSO are quite different in this stage. Their duties of embedding sustainability, attending to stakeholder relations, and educating employees are less visible. Indicatively, we report that while in the Compliance and Efficiency stages responsibility over reporting sustainability data is assumed by almost $100 \%$ of the CSOs, the respective number is only $75 \%$ in the Innovation stage. An explanation of this finding is that as companies integrate sustainability with the core of their business they also move from sustainability reporting to integrated reporting. As a result, reporting of sustainability data now becomes a responsibility of the CFO rather than the CSO. Similarly, the number of CSOs reporting that part of their responsibilities includes educating employees, learning from external sources, and managing stakeholder relations declines significantly. This decline is probably a result of the CSO delegating authority and decision rights to functional departments and local business units. While in the Efficiency stage the CSO manages and sometimes carries out all of these processes, while in the Innovation stage the CSO allocates these responsibilities to champions of sustainability throughout the organization. This explanation is consistent with the increasing importance of where champions of sustainability are located as a criterion in where to locate primary responsibility for sustainability. The question then becomes what is the role of the CSO in the Innovation stage. Our interview data shed light on this question.

According to the interviewees, the primary responsibility of the CSO in the Innovation stage is to assist with the development of the sustainability strategy as it evolves into the third stage and to develop the change strategy to support it. For example, when Steve Howard, the CSO for IKEA was hired, the first thing he did was review the company's sustainability strategy. With a Ph.D. in environmental physics and his experience in running The Climate Group, an NGO focused on climate change, he was determined to take the IKEA sustainability strategy to a new level. He said that he did not think that their strategy was visionary enough and that it did not clearly connect back to the business. Howard moved IKEA into the Innovation stage by 
pulling together the senior leadership at IKEA to discuss how the company could be prepared for long-term world changes. This discussion led to the company's new strategy as well as a framework for the business case.

During this third stage, our interview data suggest that the CSOs also have a significant role in assisting with the companies' innovation strategies. Dave Keppler, the CSO of Dow Chemical, said that senior leadership had been involved with environmental sustainability for many years. He assumed the position of CSO as the company shifted from primarily managing its footprint (Efficiency stage) to becoming market-driven in its approach to sustainability (Innovation stage). The CEO, with the Board's support, appointed him because they wanted someone who could facilitate the company's innovation while also engaging the business in the process. At the time, he was the $\mathrm{CIO}$ and he had previously been in charge of the safety strategy when it was transformed. It was a natural transition for him to assume the responsibilities of the CSO position since the facilitation expertise for it resembled the skills he mastered in his other roles. Since his passion and experience were in the area of transformation, he was a natural candidate for the job.

The interviewees highlighted that for sustainability strategies to take hold, they must be legitimized with stakeholders. The business case is a key element of the legitimization process. If this case is weak and the vision is not legitimized, the CSO is less likely to successfully carry out his or her other primary role of driving change through the organization. One of the opportunities and challenges for market-driven sustainability is that as the strategy evolves, so must the business case. According to Peter Graf, CSO of SAP, to continuously legitimize the strategy as it evolves often means developing more than one business case. The CSOs own the process of what they call the never-ending evolution of the business case(s).

As the strategy is legitimized, the CSO cultivates a sophisticated plan to bring about transformational change. Some organizational change scholars refer to this plan as a blueprint for creating the organization of the future, (Nadler, Shaw and Walton, 1995.) The CSO is situated to play a key role in this process by working with local leaders to create the blueprint that takes into account their circumstances as well as their necessary contributions to the transformation. The $\mathrm{CSO}$ is in the position to ensure organizational alignment across both functions and geographies.

Scholars have debated whether organizations are monolithic with one strong culture or pluralistic. Those who support a pluralistic view argue that organizations are usually not composed of one unified culture but rather of many distinct subcultures. This view suggests that catalysts for change can have localized impacts on the various subcultures such as functions, hierarchies, and occupational groups, even when all are embedded in an overarching dominant culture (Demers 2007). The implication for CSOs is that their change strategy must take into account these subcultures. Research shows that even in the most committed companies the process of transformation will move through the various parts of the companies at different rates (Miller 2013). This can perhaps be explained by the theory that most organizations are fragmented, with several subcultures within the dominant culture. Each of the subcultures is likely to have its own collective identity, defined as the cognitive, normative and emotional connection experienced by members of a social group because of their perceived common status (Thornton and Ocasio, 2008). Logics, i.e. belief systems that shape the cognitions and behaviors of actors, emerge from these collective identities. Therefore, the process of driving change must take into account the multiple subcultures and their own logics and identities. SAP's CSO Peter Graf, holds the pluralistic view of culture when he argues that SAP has many groups with 
varying perspectives. He claims that the strategies and messaging must be customized to the subcultures.

Elizabeth Heider, the recently appointed CSO for Skanska USA, among the largest construction and development companies in the US, says that one of her main priorities is to work in partnership with the CEO, Mike McNally, to drive transformation through the multiple businesses and parts of the company. Skanska is recognized as an industry leader in constructing sustainable buildings. ${ }^{8}$ She says that continuing to expand their leadership is a business imperative. To prove her point, she explained that during the Great Recession, the construction companies that were leaders in "green building" were the only ones to continue to grow. ${ }^{9}$ Before her appointment to the CSO position, Heider spearheaded Skanska USA Building's green building initiatives. She has been working internally to pull together the company's green initiatives since 2005. When asked why the CEO created the CSO position and promoted her into it, she said that the time was right for a more centralized and concentrated approach since the US is a growth market for Skanska. Now her role is to work alongside McNally and provide support and a vision across all four business units to elevate their performance across the company. Heider explains that Skanska USA was created through acquisitions, ending up with what she refers to as a confederation of legacy companies, each with its own culture. She has been tasked with developing a strategy for moving the company from a confederacy to a union in the sustainability realm. And yet she explains that construction is a local activity, and that while some markets are progressive others lag behind. In addition, her strategy is to support the civil construction business unit where their sustainability story is untold. She said, "We have an opportunity to raise all ships by also bringing along our subcontractors."

John Mandyck, the CSO of UTC Building \& Industrial Systems, described how his organization grew through the addition of other businesses, with sustainability becoming a unifier of the legacy companies. The organization is very diverse and includes elevators and escalators, refrigeration, heating and air conditioning, fire safety, and security. Moreover it carries more than 80 brands. Mandyck emphasized how sustainability can be used as the platform to unify the various groups by highlighting the sustainability aspects of each product line in a vertical. Thus all of the products in a vertical are branded with sustainability. The interaction of sustainability with the presence of subcultures is complex. While CSOs can devise a sustainability strategy that takes into account all of the many subcultures, they can also use the sustainability platform to unify these subcultures.

In summary, the CSO role often carries significantly more authority during the Innovation stage. The responsibilities may shift from tactical to strategic. The CSOs may not only help develop visionary, market-driven sustainability strategies, they also must devise one or more business cases as the strategies evolve. They craft an approach to legitimizing the strategies with stakeholders and devise a sophisticated plan for driving the transformational change to support the strategies through the company. These responsibilities seem to require the increased authority that the position appears to hold in this stage.

\section{CONCLUSION AND LESSONS LEARNED}

Our research shows that the role of the CSO changes as companies transition through the stages. In the first stage, Compliance, very few companies have a person holding the title of CSO or the

\footnotetext{
${ }^{8}$ Skanska, "Green building." http://www.usa.skanska.com/Markets/Green-building/

${ }^{9}$ McGraw-Hill Green Market Report, 2010.http://www.construction.com/AboutUs/2010/1112pr.asp
} 
equivalent. Those CSOs that are in place in the first stage tend to have relatively low levels of authority. It is in the second and third stages (Efficiency and Innovation) that companies begin to create the CSO position with more elevated authority. Nevertheless, many of those who were later assigned to the CSO position were already taking a strong leadership role in pushing the company from Compliance to Efficiency. Thus many of the individuals who now hold the CSO title were actively involved in every stage. However their roles and responsibilities as well as their titles varied across the stages.

In this section we will present some of the specific lessons learned by the CSOs we interviewed. We will present an overview of what the CSOs who participated in our interviews recommend for all of the stages, and will summarize how they carry out their roles in helping their companies transition through the stages. We note that we do not have any evidence that their recommendations will improve the competitiveness of other organizations or that they have improved the competitiveness of their own organizations. However, we also note that their organizations are ranked by independent providers as leaders in sustainability and each organization has made the business case for sustainability showing that their sustainability initiatives have been financially beneficial.

\subsection{Recommendations for All Stages}

Our interviewees suggested that CSOs in every stage are more successful in changing the organization when they locate themselves as close as possible to areas where sustainability can produce value for the company. In the first stage, CSOs or those who will eventually gain that title need to stay close to those who oversee compliance and risk for the company. However, as companies move through the second stage and into the third stage, the areas where sustainability will produce value will vary from company to company depending on their business and the nature of their strategy. Therefore, a CSO must assess what is significant and relevant to the company where she is employed and build the sustainability strategy accordingly. As the CSO moves through the second to the third stage, he gains authority. Thus he is critical to the successful development and communication of the business case(s) to expanded groups of stakeholders.

Those we interviewed argue that CSOs should not get too hung up on naming their company's stage or on labeling the kind of change that they are leading. Peter Graf, CSO of SAP, stated that what is compliance for one group may be a transformation for another. He suggested that CSOs keep this in mind when they are developing their action plans. Graf's point is corroborated by scholars who study the social dynamics of change. They assert that organizational change cannot be imposed in a monolithic fashion by management. Rather cultural change emerges from the interactions of the local subcultures. Thus while some subcultures may view the change as transformational, others may see it as merely transitional. As a result, the effect of the subcultures on overall organizational change is likely to be achieved in increments (Myerson and Martin 1987), with long-term change being evolutionary (Warglein 2002).

Steve Howard, CSO of IKEA, also discussed the significance of diagnosing the culture before planning a change strategy. However, unlike Graf's and Heider's descriptions of their companies' pluralistic cultures, Howard describes the IKEA culture as unified and cohesive in supporting company strategy. He suggests that a successful approach to change in a strong centralized culture will differ from strategies that will succeed in a less centralized pluralistic company. According to Beth Heider, CSO of Skanska, in a decentralized culture the CSO should 
think of the company as an organism with moving parts. Some parts of the culture will be more mature than others and may be related to the markets that each serves. Thus the CSO must gauge her strategy on a granular level. In a more cohesive culture such as IKEA's, the CSO can take a more monolithic versus a pluralistic approach to the change strategy.

Almost all of the CSOs we interviewed stressed the importance of focusing on a manageable set of sustainability-related issues each year. John Edelman, CSO of Edelman, referred to his approach as "evolutionary, not revolutionary." Steve Howard agrees. "You can't transform everything at once," said Howard. "The hardest thing about leading the change is managing the complexity, especially in a company like IKEA where the public is interested and watching our actions." Beth Heider stated that it is important to understand that this is not a "once and done" process. It will continue to morph and change. She suggests staying focused and managing the complexity.

\subsection{Efficiency and Innovation Stage}

The CSOs recommended that their counterparts in other companies get a baseline of what the company may already be doing when they first assume the role. It is important to focus on a few core issues in the beginning of this stage. And while some say that the CSO should develop a common language, others argued that it is important to learn to speak many languages - or the lexicons of a variety of stakeholder groups in order to make the business case and strategy understandable and relevant to each. One of the most difficult challenges facing the CSO in this stage is to push the company leaders and investors to get out of the "trade-off" mentality. The CSO needs to be able to discuss the sustainability strategy of the firm with investors by using the language of the capital markets.

Our interviewees recommended that as a company moves through the Efficiency stage towards the Innovation stage, the CSO should work to engage as many people and groups as possible. For example, Scott Wicker, CSO of UPS, a package delivery company and provider of specialized transportation and logistics services, described their strategy committee and working committee. Through these committees the CSO can help leaders and others in the organization think about the changes through their own area's lens. Edelman recommends working from the top down and the bottom up in this phase, since employees like to get involved.

\subsection{Innovation Stage}

It is in this stage that the role of the CSO tends to gain an increasing level of authority. Our interviewees assert that the CSO should report to the CEO and should sit on the executive team. This positioning gives the CSO not only legitimacy, but also access to the decision-makers so that she can be an advocate for sustainability in the decision-making process and can provide input on market-driven strategies. Steve Howard advocates putting the CSO on the executive team because her physical presence makes a difference in the conversation. He asserts that without this presence, sustainability goals would slip down the agenda. These recommendations are consistent with the literature on institutional entrepreneurs which suggests that those change leaders with high social positioning and power are more likely to be effective (Battilana 2007).

Many of the CSOs we interviewed take the lead in formulating vision and strategy in this stage. Several, including Steve Howard from IKEA and Alexandra Palt from L'Oreal, said that the best way to create the vision is to identify the company's unique position with respect to future global challenges. Palt argued that this is the only way to ensure that the company stays relevant and survives for the next 100 years. 
Our CSO interviewees suggest bringing together executives, internal experts, opinion leaders, and even NGOs to assist with the strategy. For example, Palt said that when she was coordinating the process for setting L'Oreal's goals for 2020, she traveled around the world to meet with NGOs so that they could provide input and challenge L'Oreal's policies and strategies. Likewise, Dave Keppler, from Dow, described their close involvement with NGOs such as the Nature Conservancy. Dow leaders also expect their NGO partners to challenge them and push them to improve their internal processes.

The CSOs recommend carefully considering how to discuss vision and strategies with stakeholder groups. Beth Heider, from Skanska, suggested that communications focus on creating a positive future, for example by creating a better world for children. Similarly, Palt suggested that the communication strategy focus on how the actions and commitments can improve people's lives rather than focusing on stimulating fear and guilt.

When asked about the knowledge, skills, and qualities that a CSO should possess to drive the change during this third stage, most agreed that a keen sense of the culture is critical, as is a sophistication in both understanding and implementing change through a complex organization. This is consistent with most CSOs being internally appointed to this position. However, when asked whether a person who has been with the company a long time is better equipped for the position than an external person with education and experience in fields related to sustainability, the interviewees were divided in their opinions. By and large they see this as a trade-off. On the one hand, those who are internal have a familiarity with the culture, understanding of the business, and credibility with the leaders. On the other hand, an external person with content expertise has a pair of fresh eyes to use in advancing the company and the knowledge to deal with the very complex issues pertaining to sustainability.

\subsection{Concluding Remarks}

We believe that our results open up a number of avenues for future research. Having documented the increased authority that CSOs have in companies that are in more advanced stages of sustainability, future research could explore how CSO incentives evolve as a result. For example, is it the case that as organizations advance through sustainability changes, the CSO is provided incentives on organization-level success metrics, such as the stock price and accounting profitability, versus more sustainability specific metrics? And what is the relative effectiveness of the two compensation strategies? Answering these questions could enhance our understanding about the incentives of CSOs in different stages and their effectiveness as change agents.

Second, we have documented that the Board of Directors is more likely to have a sustainability committee in the third stage Innovation. We still know very little about what this committee does and how it informs decision making inside the company. Nor do we know which members serve on this committee or importantly how the CSO interacts with its members. Collecting and analyzing data that help to answer these questions would contribute to the literature on corporate governance.

A third question relates to the potentially puzzling results regarding the responsibilities of CSOs in the third stage Innovation. While we find that CSO responsibilities are similar in the first two stages, Compliance and Efficiency, and that CSOs perform a wide variety of tasks, in the Innovation stage fewer CSOs perform all these tasks. Our interview data suggest that their responsibility evolves to tasks that relate to forging a strong culture and unifying the different subcultures inside the firm. Future research could explore what is the most effective strategy for achieving this and what are the consequences of these actions for organizational performance. 
Having documented the importance of sustainability champions in the third stage as a factor for locating primary responsibility for sustainability, future research could study the location of sustainability champions as a possible mechanism for the unification of subcultures inside the firm.

Finally, future research could try to understand how CSOs interact with institutional investors as their authority and responsibility evolve. Presumably, by the third stage institutional investors are aware of the increasing decision rights and influence of the CSO inside the organization. Is it the case that the CSO becomes part of the conversation between senior management and investors in these later stages? How do different types of investors, short-term and long-term oriented, react to the business case made by the CSO? How does the CSO work with the CFO, the other C-level executive apart from the CEO, who is in charge of the discussion with investors? Shedding light on these phenomena would contribute to the literature on sustainability and integrated reporting and the literature that documents capital market benefits from enhanced communication of sustainability information.

We believe that our study also suggests some interesting avenues for future research on change, at the institutional, organizational and individual levels. In a recent article, Bins, Harreld, O'Reilly and Tushman (2014) argued that organizations need to find a way to initiate transformation proactively. What is needed is a way to change before a crisis pushes the organization to transform out of fear. They suggest that companies should create growth-related goals that connect with the positive emotions of individuals and the sense of the company's identity. We propose that our interview data exhibits some evidence that endogenous tensions can create growth-related, proactive transformation related to sustainability. Our CSOs recounted how their advocacy as well as the CEO's vision for becoming a sustainable company precipitated the process of change. Beer and Walton (1987) suggested that as the leader's vision creates and structures the cognitive world of those connected to the organization, that vision becomes a logic that precipitates change in ideas, values, and behaviors. Perhaps future research could more systematically analyze the process by which a CEO develops this vision.

Another area for future research is what specifically happens in the Compliance stage that enables the company to ultimately move to Efficiency and possibly Innovation. Edelman and Suchman (1997) argue that regulations often have greater effects on organizations through the normative and cognitive processes that they set in motion than by their coercive mechanisms. They assert that constituency statute legislation gave firms the right to take stakeholder interests other than shareholders into account when making decisions. They also mention that legislative statutes are loose and that people collectively construct what it means to be in compliance. Therefore even in this first stage institutional logics are contested as organizations coalesce into fields to construct meaning. Thus the process of change most likely begins in this stage and is probably emergent rather than intentional. More exploration of the nature of these processes and possible role that they play in enabling transition to the higher stages would greatly improve our understanding. 


\section{References}

Acre, Aconas, Ethical Performance, Flag, "The CR and Sustainability Salary Survey.” (2012).

Anderson Dean, and Linda Ackerman Anderson. "Beyond Change Management: Advanced Strategies for Today's Transformational Leaders.” Jossey-Bass Pfeiffer, (2001).

Battilana, Julie. "Initiating Divergent Organizational Change: The Enabling Role of Actor's Social Position." Academy of Management Annual Meeting Proceedings (August 2007).

Beers Michael and Anna Walton. "Organizational Change and Development: New Arenas for Inquiry and Action.” Journal of Management 15 (1989): 205-228.

Binns, Andy, J. Bruce Harreld, Charles A. O'Reilly, and Michael L. Tushman. "The Art of Strategic Renewal." MIT Sloan Management Review 55, no. 2 (Winter 2014): 21-23.

Campbell, John. "Why would corporations behave in socially responsible ways? An institutional theory of corporate social responsibility." Academy of Management Review, 32 no. 3 (2007): 946 $-967$.

Dyllick, Thomas and Katrin Muff. "Clarifying the Meaning of Sustainable Business." University of St. Gallen and Business School Lausanne Working Paper (Summer 2013).

Eccles, Robert, and George Serafeim. "The Performance Frontier: Innovating for a Sustainable Strategy." Harvard Business Review 91, no. 5 (May 2013): 50-60.

Eccles, Robert, Kathy Miller, and George Serafeim. "How to Become a Sustainable Company." MIT Sloan Management Review 53, no. 4 (Summer 2012).

Edelman, Lauren and Mark Suchman. "The Legal Environments of Organizations." Annual Review of Sociology 23 (August 1997): 479-515.

Esty, D.C. and A. S. Winston, "Green to Gold: How Smart Companies Use Environmental Strategy to Innovate, Create Value, and Build Competitive Advantage." (New Haven: Yale University Press, 2006).

Footprint Talent \& WAP Sustainability Consulting. "The State of the CSO.” (2011).

Greenbiz. "State of the Profession." 2013.

http://ugs.utah.edu/sustainability-certificate/State\%20of\%20the\%20Profession\%202013.pdf

Hayagreeva Rao, Philippe Monin, and Rodolphe Durand. "Institutional Change in Toque Ville: Nouvelle Cuisine as an Identity Movement in French Gastronomy." American Journal of Sociology 108, no. 4 (January 2003): 795-843.

Hoffman, Andrew and Pratima Bansal. "Business and the Natural Environment." Oxford University Press: Oxford, U.K. (2012). 
Ioannou, Ioannis, and George Serafeim. "What Drives Corporate Social Performance? The Role of Nation-level Institutions." Journal of International Business Studies 43, no. 9 (December 2012): 834-864.

Kellogg, Katherine C. "Hot Lights and Cold Steel: Cultural and Political Toolkits for Practice Change in Surgery." Organization Science 22, no. 2 (2011): 482-502.

Lounsbury, Michael. "Institutional Sources of Practice Variation: Staffing College and University Recycling Programs." Administrative Science Quarterly 46, no. 1 (2001): 29-56.

McWilliams, Abagail and Donald Siegel. "Corporate social responsibility: A theory of the firm perspective." Academy of Management Review 26, no. 1 (2001): 117-127.

Meyer, Alan. "Adapting to environmental jolts." Administrative Science Quarterly 27, no. 4 (December 1982): 515-537.

Miller, Kathy. "Sustainability and Culture: a Case Study of Dow Chemical and Nedbank." Working paper, 2013.

Mirvens, P. and Bradley Googins. "Moving to Next Generation Corporate Citizenship." CCCD Century fur Corporate Citizenship Deutschland. Kollwitzstr 7310435 Berlin, (2009).

Nadler, David, and Michael Tushman. "Types of organizational change: From incremental improvement to discontinuous transformation." In Discontinuous change: Leading organizational transformation, ed. D. A. Nadler, R. B. Shaw, A. E. Walton, and Associates (1995): 15-34. San Francisco: Jossey-Bass.

Newman, Karen. "Organizational transformation during institutional upheaval." Academy of Management Review 25, no. 3 (July 2000): 602-619.

Nidumolu, Ram, C. K. Prahalad, and M. R. Rangaswami. "Why Sustainability is now the Key Driver of Innovation." Harvard Business Review, (September 2009).

PwC. "The Sustainability Executive: Profile and Progress." (2012).

Thornton, Patricia and William Ocasio. "Institutional Logics," In Handbook of Organizational Institutionalism. R. Greenwood, C. Oliver and R. Suddaby, Eds. Sage Publishers (2008).

Tolbert, Pamela and Lynn Zucker. "The Institutionalization of Institutional Theory." In S. Clegg, C. Hardy and W. Nord (Eds.), Handbook of organization studies (1996): 175-190. London: SAGE.

Weinreb Group. "CSO Back Story: How Chief Sustainability Officers Reached the C-Suite." (2011).

Willard, Bob. The Sustainability Advantage. New Society Publishers, $10^{\text {th }}$ Anniversary Edition (2012). 


\section{Figure 8.1}

\begin{tabular}{|c|c|c|c|}
\hline \multirow[b]{2}{*}{ Categories } & \multicolumn{3}{|c|}{ Stage of Sustainability } \\
\hline & Compliance & Efficiency & Innovation \\
\hline \multicolumn{4}{|l|}{ CSO Authority } \\
\hline Person with Primary Responsibility for Sustainability has the Title of CSO & $14 \%$ & $27 \%$ & $36 \%$ \\
\hline CSO Reports to CEO or Board of Directors & $32 \%$ & $41 \%$ & $41 \%$ \\
\hline \multicolumn{4}{|l|}{ Organizational Characteristics Related Sustainability } \\
\hline CEO or Board of Directors Ultimately Responsible for Sustainability & $73 \%$ & $86 \%$ & $59 \%$ \\
\hline Board Sustainability Committee & $32 \%$ & $27 \%$ & $64 \%$ \\
\hline \multicolumn{4}{|l|}{ CSO Responsibilities } \\
\hline Sustainability Strategy Development & $91 \%$ & $91 \%$ & $86 \%$ \\
\hline Embedding Sustainability Strategy in the Organization & $91 \%$ & $95 \%$ & $86 \%$ \\
\hline Reporting Sustainability Data & $95 \%$ & $100 \%$ & $75 \%$ \\
\hline Managing Stakeholder Relations & $82 \%$ & $82 \%$ & $68 \%$ \\
\hline Employee Education around Sustainability & $82 \%$ & $86 \%$ & $73 \%$ \\
\hline Facilities Management & $5 \%$ & $45 \%$ & $18 \%$ \\
\hline Learning from External Sources & $91 \%$ & $91 \%$ & $64 \%$ \\
\hline Determining Material Sustainability Issues & $86 \%$ & $86 \%$ & $77 \%$ \\
\hline \multicolumn{4}{|l|}{ Impact on CEO Involvement in Sustainability from CSO Appointment } \\
\hline Change in CEO Involvement in Sustainability from CSO Appointment & 2.72 & 2.62 & 2.50 \\
\hline \multicolumn{4}{|l|}{ Who Decides Where to Locate Primary Responsibility and Which Factors Affect the Decision } \\
\hline CEO or Board of Directors Decide where to Locate Primary Responsibility for Sustainability & $77 \%$ & $64 \%$ & $77 \%$ \\
\hline Breadth of Organizational Commitment to Sustainability & $55 \%$ & $68 \%$ & $55 \%$ \\
\hline Where Champions of Sustainability are Located & $18 \%$ & $23 \%$ & $36 \%$ \\
\hline Level of Commitment of Organization to Sustainability & $64 \%$ & $68 \%$ & $55 \%$ \\
\hline Sustainability Strategy of the Organization & $41 \%$ & $55 \%$ & $64 \%$ \\
\hline
\end{tabular}

Source: Authors' research

Results from a survey with 66 respondents. The Compliance, Efficiency and Innovation stages have the same number of respondents, 22 each. The figure reports frequency of survey participants that respond "Yes" to a question. For "Change in CEO Involvement in Sustainability from CSO Appointment" the average of responses is reported where 3 is "CEO Involvement has Increased," 2 is "CEO Involvement has Stayed the Same," and 1 is "CEO Involvement has Decreased." 